\title{
Os desafios da avaliação em contexto de expansão e inclusão
}

\author{
The challenges of evaluation in a context of expansion and inclusion
}

Dilvo Ristoff

Harlem

O que acontece ao sonho adiado?

Será que seca como uma passa de uva ao sol?

Será que infecciona e escorre como uma ferida purulenta?

Será que cheira mal?

Ou será que cria crosta como um doce meloso e açucarado?

O que acontece ao sonho adiado?

Talvez só se instale como um fardo pesado...

Um fardo que carregar ninguém pode.

Ou será, será que um dia explode?

(HUGHES, 1951 apud ROBERTS; JACOBS, 1989, p. 642, tradução nossa).

\section{Resumo}

Este texto discute algumas das promessas derivadas das diretivas de expansão e inclusão professadas pela Conferência Mundial de Educação Superior (CMES) de 2009, da UNESCO, e pelos Objetivos do Desenvolvimento Sustentável (ODS) de 2015, da Organização das Nações Unidas, pelo Plano Nacional de Educação de 2001 e pelo Plano Nacional de Educação de 2014. As promessas para um ensino superior inclusivo e de qualidade são muitas e ambiciosas, entre elas está o acesso à educação de qualidade para todos. Essas promessas geralmente têm sido confrontadas por múltiplos equívocos e temores, entre os quais as noções de que: (a) a expansão reduzirá a qualidade da educação; (b) a inclusão forçará a redução dos padrões de qualidade; e (c) a expansão com inclusão e qualidade no ensino superior é insustentável. O texto discute essas promessas e esses temores a partir da análise do impacto de cinco dos principais programas brasileiros de democratização do ensino superior (Prouni, Reuni, Fies, Sisu, IFs) e dos desafios que eles impõem ao Sistema Nacional de Avaliação da Educação Superior (Sinaes). Entre as conclusões está a constatação de que, embora em contextos muito específicos, alguns desses temores possam ser justificáveis, eles geralmente não encontram sustentação nos dados existentes e podem ser classificados como mitos. O último argumento é que, nos últimos doze anos, as preocupações com inclusão e avaliação, no Brasil, nos países do Mercosul e em outros países da América Latina, passaram do tabu ao totem, ou seja, de temas marginais ou proibidos (que não podiam ser discutidos, por supostamente comprometerem a qualidade) a temas que se tornaram centrais, coletivos, respeitados, reverenciados e quase sagrados, no âmbito das políticas públicas educacionais.

Palavras-chave: Avaliação. Educação superior. Expansão. Garantia da qualidade. Inclusão.

Recebido em 07/07/2018 - Aprovado em 25/09/2018

http://dx.doi.org/10.5335/rep.v26i1.8406

Centro Tecnológico, Programa de Pós-Graduação em Métodos e Gestão em Avaliação, Universidade Federal de Santa Catarina. E-mail: ristoff.dilvo@gmail.com 


\title{
Abstract
}

\begin{abstract}
The text discusses some of the promises derived from the Expansion and Inclusion Directives, as professed by the UNESCO World Conference on Higher Education (WCHE 2009) and the United Nations Organization for Sustainable Development (ODS 2015) and the 2001 and 2014 Brazilian National Education Plans. The promises for inclusive and quality higher education are many and ambitious, including access to quality education for all. These promises have often been confronted with multiple misunderstandings and fears, including the notions that: (a) expansion will reduce the quality of education; (b) inclusion will drive down quality standards; and (c) expansion with inclusion and quality in higher education is unsustainable. The text discusses these promises and fears, considering the impact of five of the main Brazilian higher education democratization programs (Prouni, Reuni, Fies, Sisu, IFs) and the challenges that they impose on the National System of Evaluation of Higher Education (Sinaes). Among the conclusions is the finding that, although in very specific contexts, some of these fears may be justifiable, they generally find no basis in existing data and can be classified as myths. The last argument is that, over the last twelve years, concerns about inclusion and evaluation in Brazil, the Mercosur countries, and other Latin American countries have gone from taboo to totem, that is, from marginal or forbidden issues that could not be discussed, for supposedly threatening quality, to themes that have become central, collective, respected, revered and almost sacred, within the scope of public educational policies.
\end{abstract}

Keywords: Evaluation. Higher education. Expansion. Quality assurance. Inclusion.

A trajetória recente da inclusão e da avaliação da educação superior brasileira poderia ser descrita como tendo sido do tabu ao totem. Há apenas alguns anos, à simples menção destas palavras ouvia-se, com frequência, a ladainha sobre o sistema já ser grande o suficiente, a inclusão ameaçar os padrões de qualidade e a avaliação só fazer sentido quando fossem dadas as condições adequadas para o exercício pleno da docência. Gestos de descaso, indiferença e às vezes de franca hostilidade indicavam que a avaliação era tida como um inoportuno e implicante intruso no dia a dia das atividades acadêmicas, uma ameaça à autonomia da universidade e um desrespeito à liberdade de cátedra. Na prática, portanto, a avaliação era rejeitada por parcela significativa do corpo docente, em especial por aquela parcela defensora de um dogma acadêmico elitista, do tempo em que a universidade era pequena e catedrática, e não grande e democrática como há anos, conforme atestam as últimas conferências mundiais da UNESCO, pretende ser.

Muito desta atitude ainda permeia o campus brasileiro, mas está, evidentemente, muito distante do que podia ser observado no início dos anos 1990. Depois da implantação do Programa de Avaliação Institucional das Universidades Brasileiras (Paiub), da aprovação da última Lei de Diretrizes e Bases da Educação Nacional (LDB) e do Plano Nacional de Educação de 2001, da criação e implementação do Sistema Nacional de Avaliação da Educação Superior (Sinaes), depois das orientações das Conferências Regionais e Mundiais da Educação Superior da UNESCO e, mais recentemente, da Agenda 2030, tanto a avaliação quanto a inclusão tornaram-se algo, por assim dizer, sagrado, totêmico, de apreciação coletiva, de respeito compartilhado. O que se percebe é que, em duas décadas, o Brasil passou de um 
patamar em que a avaliação e a inclusão eram temas terminantemente proibidos na agenda acadêmica, um tabu, para um novo patamar em que esses temas se tornaram elementos fundamentais, permanentes e estruturantes da organização de políticas e programas para a educação superior.

A Constituição de 1988 (BRASIL, 1988), ao estabelecer, em seu artigo 209, que a educação é livre à iniciativa privada mediante avaliação de qualidade pelo poder público, fez do Brasil um Estado avaliador por excelência, um país em que o aval do Estado é resultado direto da avaliação pelo Estado. Abre-se, assim, espaço para a atuação decisiva do setor privado na educação em geral e na educação superior em especial, deixando estabelecida, sem rodeios, uma vinculação direta entre a avaliação da qualidade e a regulação do sistema. Da Constituição deriva um conjunto de outras leis, decretos e portarias que reforçam esta vinculação.

Primeiramente, a Lei no 9.131/1995 (BRASIL, 1995), um ano antes da LDB, criou a avaliação periódica de instituições de ensino superior (IES) e cursos, estabelecendo que, a partir daquele momento, nenhum curso teria reconhecimento ou renovação de reconhecimento ad aeternum, o mesmo valendo para o credenciamento ou recredenciamento das instituições. Periodicamente, cursos e instituições teriam que, a partir daquela data, ser avaliados quanto a sua qualidade e sua capacidade de assegurar condições adequadas para a continuidade de suas atividades.

Um ano mais tarde, a LDB (BRASIL, 1996) vem reforçar o conceito do Estado avaliador, afirmando que cabe ao governo federal "[...] autorizar, reconhecer, credenciar, supervisionar e avaliar cursos e instituições de educação superior" (Art. 9, inciso IX). Como a Constituição estabelece que a responsabilidade educacional primeira e prioritária dos municípios deve ser o ensino fundamental, a dos estados e do Distrito Federal o ensino médio e a da União o ensino superior, é apenas natural que a educação superior se constitua eminentemente na esfera federal. Os ditames da LDB deixam, pois, evidente que o principal avaliador da educação superior é o governo federal, por intermédio de seu ministério, de suas autarquias e fundações pertinentes e das comissões por elas constituídas.

Como 93\% das IES pertencem ao sistema federal, dependendo diretamente da União para o seu processo regulatório, fica também clara a dimensão gigantesca da centralização da educação superior brasileira e o peso que esta centralização representa para a avaliação educacional, implicando, literalmente, dezenas de avaliações in loco por dia. Quando se pensa em um sistema em constante expansão e com metas ambiciosas de expansão estabelecidas para a próxima década, percebe-se que, da forma como está estruturado o Ministério da Educação (MEC), hoje, o país não reúne condições adequadas para suportar o peso de tantas avaliações diárias sem pôr em sério risco a qualidade do trabalho avaliativo e, consequentemente, das decisões regulatórias. 
A LDB estabelece ainda que a avaliação institucional e de cursos só se completa se gerar atos regulatórios, de autorização, reconhecimento, renovação de reconhecimento de cursos e credenciamento e recredenciamento de instituições.

A Lei no 10.172, de 2001 (Plano Nacional de Educação - PNE), por sua vez, expõe a visão de que "[...] nenhum país pode aspirar a ser desenvolvido e independente sem um forte sistema de educação superior" (BRASIL, 2001, não paginado). A legislação estabelece igualmente como diretriz a expansão do sistema com qualidade, o que significa dizer com avaliação. Para tanto, prevê a criação de um sistema nacional de avaliação. Na educação superior, esse sistema veio a ser, alguns anos depois, o Sistema Nacional de Avaliação da Educação Superior (Sinaes), instituído por lei. O Sinaes, não obstante a sua doutrina original formativa, veio uma vez mais reforçar a ideia de que a regulação deve ter a avaliação como seu referencial básico.

Mais importante, o PNE de 2001, assim como as declarações das últimas conferências regionais e mundiais da educação superior, aponta para o papel fundamental da educação superior para a construção de uma imagem de futuro para 0 país, qual seja, a consolidação de uma nação: (1) soberana, dona de seu destino e, para tanto, avançada nas artes, nas ciências e nas tecnologias; (2) democrática, isto é, a serviço do povo e não de oligarquias ou grupos privilegiados; (3) inclusiva, isto é, que pense um sistema de educação superior de acesso amplo à população, com especial atenção à inclusão dos grupos historicamente excluídos; e (4) emancipadora, isto é, capaz de contribuir para a mobilidade social dos indivíduos, permitindo a eles que, graças à educação de qualidade recebida, possam gerar as suas próprias oportunidades na vida, livrando-se da infantilização da permanente dependência e tornando-se capazes de contribuir, como energias criativas que são, para o desenvolvimento do país.

Nas últimas duas décadas, as estratégias para perseguir esta visão têm sido: (1) expandir; (2) incluir; (3) garantir qualidade para regular; (4) fazer uso de novas tecnologias; (5) formar professores; e (6) internacionalizar. A expansão, a inclusão e a garantia da qualidade merecem atenção especial.

A expansão da educação superior tem sido significativa nos últimos 25 anos. Dados do Censo da Educação Superior do Instituto Nacional de Estudos e Pesquisas Educacionais Anísio Teixeira (Inep) mostram que, em 1991, o Brasil tinha cerca de 1,5 milhão de matrículas. Em 2016, esse número chegou a mais de 8 milhões. Trata-se, portanto, de um crescimento significativo. Tal aumento das matrículas foi, por óbvio, acompanhado de expressivo aumento no número de cursos e instituições, com forte impacto sobre a atividade avaliativa. 
A primeira pergunta que surge é: era necessário expandir a educação superior com tamanha velocidade?

Os dados globais indicam que sim, que expandir era e permanece sendo uma urgência para que o país não continue a perder os cérebros, as sensibilidades e as energias criativas de gerações inteiras de estudantes. Embora o sistema brasileiro de educação superior pareça grande, ele na verdade é um sistema proporcionalmente pequeno, estando entre os menores na comparação com os países mais desenvolvidos e mesmo na comparação com muitos dos vizinhos do Brasil na América Latina. Exemplificando: a taxa de escolarização líquida do Brasil em 2003 estava em torno de 9\%, quando países europeus, Estados Unidos, Canadá e alguns países asiáticos já ostentavam, em geral, mais de 40\%. O sistema brasileiro de acesso à educação superior era, em 2003, para usar a expressão oriunda da classificação dos sistemas de acesso de Martin Trow (2005), um sistema de elite. Era, portanto, necessário expandir, pois os números da taxa de escolarização não são sem consequência: eles indicam quantos de cada 100 jovens o país potencializa para que se transformem em energias criativas capazes de serem colocadas a serviço do desenvolvimento do país. Ao potencializar apenas 9 de cada 100 jovens de 18 a 24 anos para estudos avançados, e com o não aproveitamento do potencial criativo de 91 de cada 100, o sonho de construir uma nação soberana, avançada nas artes, nas ciências e nas tecnologias, nada mais seria que uma fantasia. Era, pois, necessário expandir.

Graças à expansão dos últimos anos, o Brasil atingiu uma taxa de escolarização líquida de $21 \%$, melhorando um pouco o seu fluxo educacional. Atingiu, ao mesmo tempo, uma taxa bruta de $30 \%$, permitindo que fosse paga um pouco da sua dívida com as gerações que perderam a idade "correta" para chegar à educação superior. Cabe destacar que cerca da metade dos 8 milhões de estudantes matriculados na graduação tem mais de 24 anos e que cerca de 700 mil têm mais de 40 anos de idade. Este enorme contingente de estudantes não frequentou a educação superior na idade correta (18 a 24 anos) não porque não a buscou, mas, principalmente, porque (1) o setor público era, até recentemente, pequeno e altamente competitivo e (2) o setor privado, por ser pago, cobrava preços proibitivos para grande parte da população. Com as políticas de democratização do acesso e da permanência dos últimos anos, estes estudantes viram surgir a sua oportunidade de frequentar a graduação, o que explica os altos percentuais da taxa de escolarização bruta.

Com governos pouco dispostos a expandir o sistema universitário público, a expansão brasileira se deu majoritariamente pelo setor privado. O que se observa é que, enquanto o setor privado cresceu nos últimos 25 anos em ritmo alucinado $(531 \%)$, o setor público cresceu, no mesmo período, em ritmo bem mais moderado 
(228\%). Ambos os setores, portanto, cresceram, mas o crescimento acelerado do setor privado é o que explica o porquê de $75 \%$ das matrículas da educação superior serem privadas, ou, em outras palavras, estarem em instituições privadas. Explicando melhor: das 8 milhões de matrículas, o setor privado detém um pouco mais de 6 milhões. Destas 6 milhões, mais de 3 milhões são diretamente financiadas pelo governo federal, quer por renúncia fiscal, via Programa Universidade para Todos (Prouni), quer por financiamento estudantil, via Fundo de Financiamento Estudantil (Fies). Isso significa que, em 2015, 50,4\% das matrículas do setor privado eram financiadas pelo governo federal. Há que se acrescentar a isso, ainda, outros sistemas de bolsas e auxílios oferecidos por estados e municípios. Ou seja, a educação superior brasileira está longe de ser tão privada quanto parece. O que se constata é que as matrículas da graduação, graças principalmente aos dois grandes programas de inclusão vigentes, são majoritariamente públicas, ou seja, financiadas pelo poder público, embora abrigadas em sua maioria pelo setor privado.

As políticas de inclusão na educação superior, é preciso que se destaque, têm origem nas orientações internacionais, a começar pela Conferência Mundial de Educação Superior da UNESCO, de 1998, e reafirmando-se pela Conferência Mundial de 2009 e, mais recentemente, pela Agenda 2030, da Organização das Nações Unidas, que estabelece as metas para o desenvolvimento sustentável dos próximos anos. No seu chamamento à ação, a Conferência Mundial de 2009 expressa, com muita clareza, a ideia de que devem ser promovidas ações para "garantir igualdade de acesso aos grupos sociais sub-representados" (UNESCO, 2009, p. 11). Entre as metas para o desenvolvimento sustentável da Agenda 2030, está a meta quatro, que busca "assegurar educação inclusiva e de qualidade para todos". Percebe-se, pois, que o Brasil tem estado em sintonia com o esforço internacionalmente proclamado e demandado.

Este esforço de inclusão do Brasil tem se expressado em um conjunto de programas e ações que merecem ser, ainda que brevemente, comentados. São eles: a implantação do Prouni; a implantação do Programa de Reestruturação e Interiorização das Universidades Federais (Reuni); a criação de novas universidades federais; o redesenho do Fies, em 2010; a implantação do Sistema de Seleção Unificada (Sisu) e da Lei das Cotas; e a criação dos Institutos Federais de Educação Tecnológica (IFs).

Com relação ao Prouni, cabe destacar que se trata de um programa de bolsas do qual já participaram mais de 1,3 milhão de estudantes pobres, $52 \%$ dos quais afrodescendentes. Desses, em 2015, mais de 500 mil já eram graduados. Para melhor entender o significado deste número, basta lembrar que ele representa o equivalente a cinco gerações de formados por todas as universidades federais do país, 
que formam, juntas, em torno de 100 mil estudantes por ano. $\mathrm{O}$ impacto desses números sobre a política de inclusão educacional no país é incontestável.

O Reuni, programa de reestruturação, recuperação e interiorização das universidades federais, por sua vez, criou mais de 170 novos campi, e o seu impacto sobre a inclusão se deve principalmente à oferta de ensino público e gratuito em regiões e cidades do interior do país, historicamente desassistidas.

Também foram criadas 18 novas universidades federais, muitas com vários campi, também com forte impacto sobre a inclusão de grupos historicamente excluídos, pois estas instituições, em sua maioria, foram instaladas em pequenas cidades do interior, tendo já sido desenhadas na sua origem com uma política de acesso em sintonia com os programas de expansão e inclusão do governo federal.

Da mesma forma, a partir de 2010, o Fies tornou-se um programa com juros altamente subsidiados e com gratuidade para estudantes das carreiras de professor e de médico, que, após se graduarem, atuem nas redes públicas. De 2010 a 2015, mais de 2,1 milhões de contratos foram assinados. Não obstante as recentes restrições impostas pelo governo Temer, o número de contratos vigentes ainda permanece significativo.

O Sisu, voltado para a democratização do acesso às instituições públicas e gratuitas, tem crescido ano a ano, tornando-se, hoje, combinado ao sistema de cotas, implementado a partir de 2013, um substituto valioso do vestibular tradicional. Graças à Lei das Cotas, já em 2016, todas as instituições federais de educação superior (Ifes) haviam atingido a meta de $50 \%$ de estudantes oriundos da escola pública em todos os seus cursos e turnos. Esse percentual de $50 \%$ pode parecer pouco para os que buscam a paridade com os $87 \%$ de matrículas públicas do ensino médio. Trata-se, no entanto, de um percentual altamente significativo para a inclusão de estudantes da escola pública em cursos de alta demanda e competitividade. Em algumas poucas instituições, é preciso destacar, o percentual de estudantes oriundos da escola pública, em todos os seus cursos, aproxima-se hoje da representação das matrículas públicas de ensino médio. São poucas, no entanto! Mesmo assim, o que se observa é que, ano após ano, o Sisu ganha espaço, e o antigo vestibular - pequeno, estadualizado, pago e com mobilidade restrita aos ricos - aos poucos vai se tornando coisa do passado, cedendo lugar a um processo seletivo amplo, nacional, democrático, gratuito, com referencial nacional de qualidade e com oportunidade de mobilidade para todos.

Por último, os institutos federais (IFs) foram criados para oferecer formação técnica aos jovens, em especial do interior do país, e formar professores de física, matemática, química e biologia. Os IFs, é bom lembrar, devem reservar $20 \%$ de suas vagas a candidatos à profissão de professor. Esses institutos foram semeados 
pelo país durante o período em que Luiz Inácio Lula da Silva e Dilma Rouseff estiveram na presidência, tendo o número de escolas em funcionamento crescido de 140 , em 2002 , para 644 , em 2015 , a grande maioria em pequenas cidades do interior do país.

Outros programas de democratização merecem ser citados pelo forte impacto que tiveram em alguns espaços. Primeiramente, destaca-se o Programa Nacional de Assistência Estudantil (Pnaes), criado para atender estudantes carentes das universidades federais - programa cujo orçamento, em seis anos, saltou de 100 milhões para mais de 1 bilhão de reais, com forte impacto sobre a democratização das universidades federais. A versão estadual deste programa é o Pnaest, que tem beneficiado as 28 IES estaduais que atualmente participam do Sisu.

O Programa Bolsa Permanência tem tido impacto mais modesto, mas complementa, nas Ifes, o orçamento destinado às políticas de inclusão e, nas IES privadas, auxilia na permanência de prounistas extremamente carentes, buscando impedir que estes deixem os seus estudos por incapacidade financeira para se sustentarem.

Por último, mas não menos importante, tem-se o Programa Institucional de Bolsas de Iniciação à Docência (Pibid). Além de suas virtudes acadêmicas de aproximar as escolas e as secretarias estaduais e municipais dos cursos de graduação e pós-graduação, tornando a formação do professor uma tarefa que envolva os atores pertinentes, o Pibid também tem uma face democratizante, pois está voltado àquela parcela da população universitária mais carente, oriunda da escola pública, e que há muito clamava por um programa de valorização desta natureza, a exemplo do que se tem para a iniciação científica. O Pibid é um programa que, embora de custo anual elevado, constitui-se em importante contraponto ao alto custo social que advém da falta de valorização do magistério, da baixa atratividade das licenciaturas, da alta evasão estudantil nos cursos de licenciatura, da formação inadequada e do improviso.

Esses programas de democratização vêm, nos últimos anos, alterando dramaticamente as feições do campus brasileiro. Sobre este tema, foram publicados, recentemente, pelo Grupo Estratégico de Análise da Educação Superior, dois estudos de minha autoria, ambos publicados pela Flacso/Brasil e disponíveis gratuitamente on-line. ${ }^{1}$ Os estudos discutem a mudança do perfil dos estudantes de graduação, a partir da análise do questionário socioeconômico do Exame Nacional do Desempenho do Estudante (Enade), e exploram cinco indicadores de inclusão de estudantes na educação superior: renda familiar do estudante; origem escolar (escola pública ou privada); cor da pele; escolaridade dos pais; e trabalho (se o aluno é trabalhador e se sustenta ou não). O objetivo geral foi verificar até que ponto as políticas e os programas de expansão, interiorização e inclusão dos últimos anos 
impactaram o perfil socioeconômico dos estudantes do campus brasileiro como um todo e, mais especificamente, dos cursos de graduação de alta, média e baixa demandas. Foram analisados 43 cursos que participaram, com comparabilidade, dos três ciclos completos do Enade.

Com relação à renda familiar dos estudantes, pode-se afirmar que (1) o campus como um todo é mais rico do que a sociedade brasileira. As famílias brasileiras com renda superior a 10 salários mínimos (ricos) representam 7\%. O que os dados revelam é que somente as licenciaturas e a Pedagogia se aproximam deste percentual. Exemplificando: Medicina tem, percentualmente, em torno de 6 vezes mais estudantes ricos e Odontologia, 4 vezes mais estudantes ricos do que a população brasileira, enquanto História, assim como as licenciaturas em geral, guarda estreita paridade com a sociedade. Ainda, (2) a cada edição do Enade, percebe-se que o número de ricos no campus diminui, abrindo espaço para estudantes das faixas de renda mais baixas. Esta redução do percentual de ricos pode ser observada em todos os 43 cursos analisados. Exemplificando: Medicina teve uma redução no percentual dos estudantes mais ricos, de 67\% para 34\%; Administração, de 21\% para $13 \%$; Odontologia, de 56\% para 19\%; Psicologia, de $32 \%$ para $16 \%$; e Pedagogia, de $8 \%$ para $4 \%$. Percebe-se que, enquanto o desafio da Medicina ainda continua sendo o de abrigar estudantes pobres, o da Pedagogia é de atrair estudantes das faixas de renda mais altas. O que vale para a Pedagogia vale, como um todo, para as licenciaturas em geral. Além disso, (3) pode-se afirmar que, não obstante a redução expressiva de estudantes ricos, observada nos últimos anos na grande maioria dos cursos, o campus continua, como já destacado, não só mais rico que a sociedade, mas também porta-voz de um verdadeiro apartheid econômico. Destaque-se, por exemplo, que há quase seis vezes mais estudantes pobres na Pedagogia do que na Medicina, e cerca de três vezes mais estudantes pobres nas licenciaturas do que na Odontologia, indicando que há, no campus, apesar do forte processo de democratização dos últimos anos, diferenças profundas entre os estudantes, o que demanda dos gestores educacionais dedicação abnegada ao processo integrativo e atenção redobrada às dificuldades específicas dos estudantes mais pobres.

O mesmo pode ser dito em relação à origem escolar: a cada edição do Enade, constata-se que mais alunos oriundos do ensino médio público chegam à universidade, tendo passado de $46 \%$ para $60 \%$ do primeiro para o terceiro ciclo do exame. Essa mudança pode ser observada em todos os 43 cursos analisados, embora tenha se mostrado mais rápida nos cursos de baixa demanda. Exemplificando: Medicina aumentou a presença de alunos da escola pública em apenas $2 \%$, enquanto em Pedagogia o aumento foi de 7\%. Tanto em Pedagogia como nas licenciaturas em 
geral, os percentuais de alunos oriundos da escola pública estão próximos à representação das matrículas públicas neste nível de ensino.

Em relação à cor da pele dos estudantes, é possível afirmar que a cada ano a educação superior recebe mais estudantes afrodescendentes e indígenas. Mesmo assim, o campus como um todo (1) continua sendo, em média, $20 \%$ mais branco que a sociedade e (2) alguns cursos de alta demanda continuam sendo eminentemente brancos, com percentuais de estudantes brancos bem acima dos $48 \%$ que este grupo representa na sociedade brasileira. Fica evidente, no entanto, que, em todos os cursos, uma mudança importante vem ocorrendo na cor da pele do alunado. Exemplificando: em Psicologia, o percentual de brancos caiu de $77 \%$ para $66 \%$, do primeiro para o terceiro ciclo do Enade; em Medicina, de 80\% para 74\%; em Ciências Contábeis, de $65 \%$ para 59\%. E assim ocorreu em todos os cursos. O ritmo da mudança, em alguns cursos, pode não ser o desejado pelos que buscam a oportunidade de acesso, mas é inegável que a mudança está acontecendo de forma constante e segura.

A mudança mais profunda, no entanto, parece ser esta: a cada ano, mais filhos de pais sem educação superior chegam ao campus e passam a ocupar espaço em todos os cursos. Exemplificando: no primeiro ciclo do Enade, os filhos de pais com escolaridade superior representavam 69\%. No terceiro ciclo, este percentual caiu para $43 \%$. Em Odontologia, a queda foi de 53\% para 31\%; em Psicologia, de $30 \%$ para 19\%; em História, de $12 \%$ para $10 \%$. Ao se constatar que pais com escolaridade superior, em geral, têm filhos com escolaridade superior, é possível inferir que esta mudança tem caráter revolucionário. A se confirmar esta tendência, é possível afirmar que os filhos de prounistas, jovens que hoje representam a primeira geração a chegar à educação superior, terão, na grande maioria dos casos, filhos com nível de escolaridade superior.

Cabe, por fim, destacar que (a) a maioria dos estudantes brasileiros são estudantes trabalhadores; (b) aproximadamente $20 \%$ dos estudantes que trabalham respondem pelo próprio sustento; (c) a grande maioria dos estudantes das licenciaturas são estudantes trabalhadores; e (d) os estudantes trabalhadores estão mais fortemente presentes nos cursos de baixa demanda.

Os dados mostram, portanto, que estas cinco variáveis têm forte correlação. Revelam, também, os avanços ocorridos nos últimos anos, as dificuldades pelo processo de democratização da educação superior, alertando os militantes da educação para os impactos desta democratização sobre a qualidade e os processos avaliativos.

A expansão e a inclusão têm, em geral, sido responsabilizadas por uma suposta baixa qualidade da educação superior. O seguinte depoimento é emblemático desse 
tipo de responsabilização: "Temos que confessar que às vezes recebemos cartas ou reclamações de indivíduos detentores do título de bacharel e cujo estilo e ortografia demonstram total e vergonhosa ignorância".

Quantas vezes constatamos exatamente isto! O texto supracitado, no entanto, foi publicado na França em 1820.

Quando li o texto a seguir, entretanto, pude ver, diante de mim, os estudantes das faculdades de Letras que conheço: "A ortografia dos estudantes de Letras chegou a uma tal deficiência que [nossa universidade] se viu obrigada a criar uma nova disciplina, com o objetivo único de corrigir os erros de linguagem dos estudantes".

Ledo engano: o texto em questão foi publicado na França em 1886. C $\mathrm{C}$ m paremos, então, os textos franceses, supracitados, com o texto a seguir: "O ensino médio se primariza... Os alunos das faculdades não sabem escrever corretamente, não possuem vocabulário exato e variado, não têm nem conhecimento gramatical nem análise lógica, nem método de exposição escrita e oral".

Este texto também é francês, só que de 1929, ou seja, publicado mais de um século depois do primeiro, mostrando que o problema da qualidade ou da percepção da falta de qualidade é, se não perene, pelo menos duradouro.

Os três textos franceses supracitados constam em apresentação em PowerPoint feita por Javier Vidal, ${ }^{2}$ professor do Departamento de Psicologia, Sociologia e Filosofia da Universidad de León, Espanha, durante evento realizado na Universidad de Valencia, em março de 2013, organizado no contexto do projeto Infoaces, Sistema de Indicadores de Instituciones de Educación Superior en América Latina.

Da mesma forma, vários outros exemplos, da França, dos Estados Unidos, da Inglaterra, da Argentina e de outros países, poderiam ser citados para sustentar a tese de que a questão da qualidade é perene e necessita ser constantemente recontextualizada, para ser adequadamente compreendida. É importante dizer que a questão não se aplica somente ao ensino, já que também na pesquisa a relação da universidade com a sociedade tem sido conturbada. Quem não se lembra das críticas sarcásticas de Jonathan Swift aos pesquisadores ingleses de seu tempo, eternizada em sua obra As viagens de Gulliver, de 1726. Dois séculos mais tarde, T. H. Huxley, eminente cientista britânico, parece corroborar as observações do ficcionista ao escrever: "[...] o estrangeiro que desejar conhecer a atividade científica ou literária da Inglaterra moderna perderá tempo e esforço se visitar nossas universidades com este objetivo" (HUXLEY, 1895 apud LYONS, 1983, p. 120, tradução nossa).

Sem precisar retornar às críticas de Sócrates aos sofistas de seu tempo, fica evidente que que estes e muitos outros depoimentos revelam que a preocupação com a qualidade tem sido constante ao longo dos anos. Esta preocupação, no entan- 
to, não impediu que os mais diferentes povos continuassem a acreditar no potencial criativo da inclusão, sustentando a tese de que o problema da qualidade, embora merecedor de atenção, é sempre menos grave do que o da exclusão. Por isso mesmo, o apavoramento brasileiro com a qualidade por causa da inclusão e da expansão não deve se constituir em justificativa para que se criem empecilhos para que esta importante política educacional e social logre êxito.

Fica, pois, evidente que, para que a expansão e a inclusão não sejam transformadas em vilãs da baixa qualidade, há que se superar certos mitos, fortemente arraigados entre nós:

a) Mito 1 - A expansão deve ser contida porque a quantidade é inimiga da qualidade.

A crença de que só o pequeno é bom e bonito talvez se aplique a bonsais, não a seres humanos, que precisam desenvolver plenamente as suas potencialidades. Se fosse verdade que quantidade é inimiga da qualidade, o Brasil deveria ter um dos mais qualificados sistemas educacionais do planeta, pelo simples fato de que, proporcionalmente, tem um sistema pequeno, com apenas $21 \%$ de taxa de escolarização líquida, enquanto países da Europa, há décadas têm mais de $40 \%$. Ninguém, no entanto, ousaria afirmar que a educação superior tenha mais qualidade que o sistema educacional alemão ou francês ou britânico. Que a quantidade é inimiga da qualidade é um mito sustentado (1) pelo desconhecimento do que de fato era a escola do passado, (2) pela falácia do presenteísmo, que julga o passado a partir de critérios do presente, e (3) pelo saudosismo dos tempos em que o ensino básico atendia a poucos e a educação superior a quase ninguém. Defender, no entanto, alta qualidade para poucos equivale a preservar regalias de grupos oligárquicos, que buscam educação exclusiva para que os seus filhos possam melhor se instrumentalizar para preservarem os seus privilégios. Este sistema odioso já não encontra mais sustentação nos dias de hoje, pois já está entranhada no tecido social a certeza de que o elitismo precisa ser rompido e substituído por um sistema que assegure oportunidade e qualidade para todos e não apenas para alguns.

b) Mito 2 - A expansão levará ao desemprego de profissionais altamente qualificados.

Cabe destacar que, em 1970, os médicos brasileiros propuseram e o MEC, sob a liderança do ministro Jarbas Passarinho, aceitou não abrir mais nenhum curso de Medicina por vários anos, porque, supostamente, já havia médicos demais e, ao continuar a expansão, criar-se-iam uma banalização da medicina e uma legião de médicos desempregados em seis anos. É im- 
portante lembrar que estávamos em 1970, quando - os mais velhos irão se lembrar - o Brasil cantava, para celebrar a busca do tricampeonato na Copa do Mundo do México: "Noventa milhões em ação, pra frente, Brasil! Salve a seleção!", numa referência ao número de brasileiros da época. Em 1970, convém destacar, o Brasil não havia formado um único médico em muitas unidades da federação, especialmente nas Regiões Norte, Nordeste e Centro-Oeste. Tratava-se, portanto, não de uma defesa de interesses nacionais, mas de interesses de uma corporação, incapaz de sequer considerar a possibilidade de que, 30 anos depois, o Brasil pudesse ter uma população bem maior e que as regiões inteiras viessem a se desenvolver minimamente. Esta ideia do surgimento de uma suposta legião de desempregados com curso superior está baseada no que poderíamos chamar de o terceiro mito com relação à educação universitária.

c) Mito 3 - A única função da educação superior é profissionalizar.

A realidade mostra que não é. O interessante é que, embora em geral saibamos que a vida, a literatura, a história, as estatísticas estão repletas de exemplos de que não vale a pena transformar o profissionalismo em obsessão, não conseguimos impedir que isso emagreça a vida acadêmica no campus. Creio que concordaríamos todos que, se é verdade que não convém viver a vida de forma errática e sem propósito, é também verdade que é inaceitável que vivamos como abelhas ou formigas, como seres geneticamente programados e pré-determinados (como que a dizer: "Você vai ser rainha, você obreira, você soldado"), seguindo repetidamente por caminhos já trilhados. Ah, mas como é difícil dizer aos alunos que não convém ser escravo de objetivos que, muitas vezes, sequer são nossos, ou de objetivos que, embora nos satisfaçam aos 18, descobrimos tolos, pífios e vazios aos 30 anos!!! É também difícil convencer os professores de que os dados (refiro-me aos dados do Instituto Brasileiro de Geografia e Estatística) indicam que só um terço dos engenheiros formados exerce a Engenharia; só $75 \%$ dos médicos exerce a Medicina; só um terço dos bacharéis em Direito trabalha com Direito; só $20 \%$ dos profissionais da Comunicação Social; e, claro, pouquíssimos professores licenciados atuam como professores. $\mathrm{O}$ estudo do professor Edson Nunes (NUNES; CARVALHO, 2006), ex-presidente do Conselho Nacional de Educação, que trata justamente da relação entre o ensino e o exercício profissional, deveria ser um alerta para todos nós, por deixar claro que a educação superior, muito além de ser formadora de profissionais, é uma liberadora de energias criativas, uma poderosa geradora de oportunidades para cidadãos-profissionais competentes em todas as áreas do conhe- 
cimento, cidadãos-profissionais que a sociedade, por ser sempre muito mais dinâmica do que as estruturas educacionais vigentes, chama, por absoluta necessidade.

d) Mito 4 - A inclusão levará a uma redução de standards e à baixa qualidade. Outro temor professado no meio acadêmico é que a inclusão de estudantes oriundos de grupos sub-representados levará ao afrouxamento de padrões e fará com que a qualidade da graduação piore. A asserção, no entanto, não encontra sustentação nos dados. Tanto os dados do Prouni quanto os do Sisu e de pesquisas localizadas de várias instituições mostram que estamos diante de mais um mito.

Vejamos, por exemplo, a comparação dos dados do desempenho dos prounistas e dos demais estudantes no Enade. Convém, antes, no entanto, relembrar que a prova do Enade é realizada de três em três anos e aplicada a grupos de áreas: ano I, aplicada ao grupo 1 (basicamente, cursos da saúde e áreas agrárias); ano II, ao grupo 2 (basicamente, cursos das engenharias e das licenciaturas); ano III, ao grupo 3 (basicamente, cursos das ciências sociais aplicadas e das ciências jurídicas). No ano IV, o Enade é de novo aplicado ao grupo I; no ano V, ao grupo II; e assim sucessivamente. Vejamos, então, o desempenho dos prounistas em comparação com os demais estudantes por meio da Figura 1.

Figura 1 - Desempenho dos prounistas

\section{Desempenho dos Prounistas}

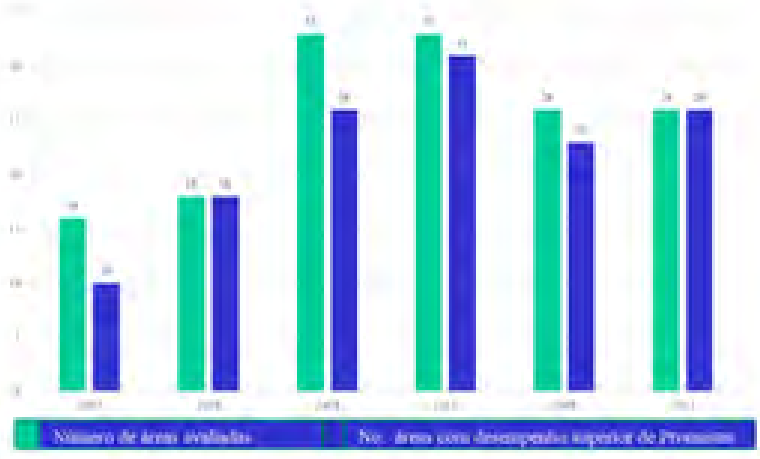

Fonte: MEC/Inep/Enade, 2007 a 2012. 
O que os dados apresentados na Figura 1 mostram é que, no grupo 1, os prounistas tiveram, em 2007, desempenho superior ao dos não prounistas em 10 de 16 áreas avaliadas, já em 2010, foi em todas as 18 áreas avaliadas. No grupo 2, os prounistas tiveram, em 2008, desempenho superior em 26 de 33 áreas avaliadas, já em 2011, foi em 31 de 33 áreas avaliadas. No grupo 3, o desempenho foi superior em 23 de 26 áreas avaliadas em 2009, ao passo que foi superior em todas as 26 áreas avaliadas em 2012.

Diante desses dados, é difícil continuar a afirmar, no diapasão proposto pelos artigos críticos ao Prouni, que a criação do programa tenha, de alguma forma, contribuído para a baixa da qualidade do ensino superior privado. A constatação é que os dados indicam exatamente o contrário.

A tendência, em geral, é atribuir o melhor desempenho dos prounistas a uma valorização maior da oportunidade que esses estudantes tiveram para se tornarem os primeiros membros das suas famílias a frequentar a educação superior. Sua tendência, portanto, seria de se agarrar de unhas e dentes à oportunidade recebida, transformando assim a satisfação e a valorização da conquista em maior dedicação aos estudos. A julgar por estudos localizados que demonstram que a taxa de evasão desses estudantes tende a ser menor e a taxa de titulação maior (MENDES JUNIOR, 2014), é provável que esta afirmação seja verdadeira, embora não haja estudos que a confirmem categoricamente. O que se sabe, graças a cruzamentos realizados pelo Inep, é que os prounistas têm, já quando do ingresso, desempenho superior ao dos pagantes e fiesistas (Figura 2).

Figura 2 - Desempenho de prounistas no Exame Nacional do Ensino Médio (Enem)

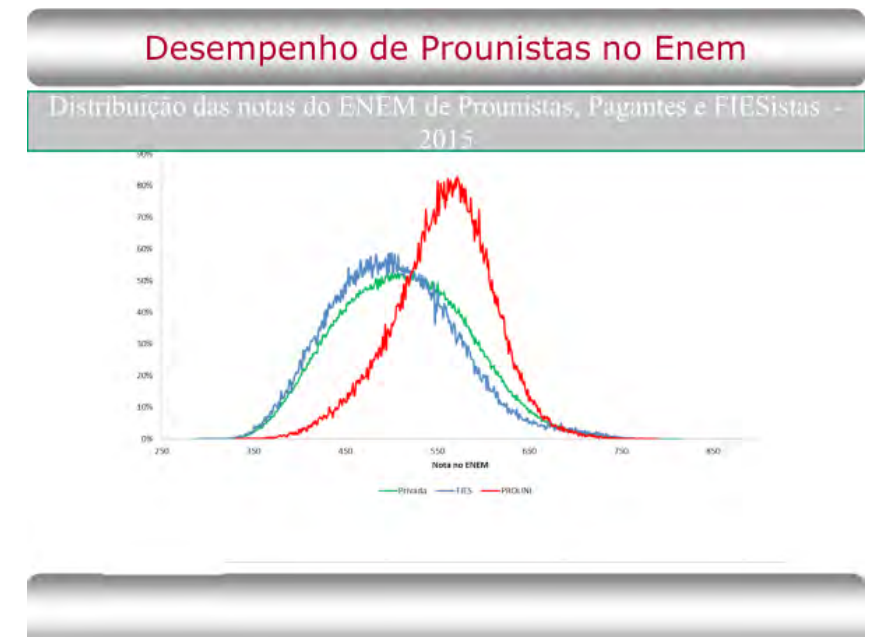

Fonte: MEC/Inep/Enem/Prouni/Fies/Censo da Educação Superior, 2015. 
O que se observa é que, enquanto os pagantes e fiesistas têm seus escores no Enem altamente concentrados em torno dos 450 pontos, os prounistas concentram-se mais solidamente em torno de 550 pontos, indicando, primeiro, que eles já são academicamente mais preparados quando do ingresso e, segundo, que a disputa, com exigência de no mínimo 450 pontos, para concorrer à bolsa do Prouni, permite a seleção de estudantes com escores acima do mínimo exigido.

No tocante ao Prouni, portanto, a afirmação de que a inclusão seja a responsável pela piora da qualidade da graduação não procede. Pode-se afirmar, a partir da análise dos dados, que, ao contrário, o Prouni passou a levar ao campus privado alunos mais bem preparados do que os alunos que até então o frequentavam. Foi em função desta constatação que, em 2015, o MEC decidiu estender a mesma exigência aos estudantes que concorrem ao Fies. Em breve, a se manter a política de seleção implantada em 2015, será possível constatar que também o Fies trará ao campus alunos mais bem preparados.

O mesmo se aplica em relação ao Sisu, utilizado por universidades e institutos federais e por algumas universidades estaduais. Combinado à Lei das Cotas, o Sisu tem se tornado um importante fator de inclusão. Também no Sisu as notas do Enem são utilizadas no processo seletivo, permitindo, basicamente, seis rotas distintas de competição: ampla concorrência, quatro rotas para estudantes oriundos da escola pública, dependendo da cor da pele do estudante e da renda familiar, e as ações afirmativas próprias das instituições participantes. O que se constata no Sisu é que os participantes da ampla concorrência, em geral, têm escores um pouco mais altos do que os cotistas. A Figura 3 apresenta alguns exemplos na faixa dos escores mais altos.

Figura 3 - Notas de corte por curso - faixa de 700 pontos no Enem

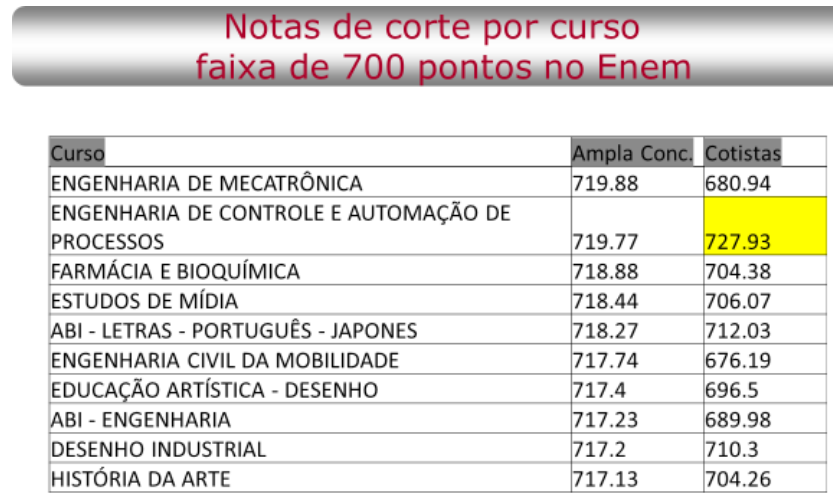

Fonte: Sesu/MEC, 2015. 
Os escores estão numa escala de 1.000 pontos e, por isso mesmo, ficamos com uma primeira impressão de que a diferença é enorme. Quando transformamos esta escala de 1.000 em uma escala de 10, com a qual os professores brasileiros estão acostumados a avaliar os seus estudantes, percebemos, surpresos, que a diferença entre os escores é insignificante, pífia (uma diferença máxima de 4 décimos, algo que os professores normalmente costumam desfazer nos arredondamentos), facilmente superável com alguma dedicação a mais do estudante ou com algum reforço pedagógico ofertado por instituições minimamente comprometidas com a inclusão.

A diferença, portanto, é insuficiente para justificar a afirmativa de que o processo de inclusão, via Sisu e Lei das Cotas, traz alunos muito mais fracos ao campus e que, em função disso, a qualidade vai piorar. Se é verdade que o estudante cotista valoriza muito mais a vaga conseguida do que os demais, então o seu esforço pessoal adicional, mesmo sem apoio pedagógico adicional (que sempre é recomendável!), compensará com vantagem os décimos que lhe faltam.

Conforme estudo realizado por Alvaro Alberto Ferreira Mendes Junior (2014), na Universidade Estadual do Rio de Janeiro, instituição pioneira na implantação de sistema de cotas no Brasil, embora o desempenho dos cotistas seja, em média, inferior ao dos demais estudantes, as suas taxas de evasão e abandono são menores e as suas taxas de titulação, invariavelmente, maiores. Outros estudos localizados de várias universidades públicas, entre elas, Universidade de Brasília, Universidade Federal da Bahia e Universidade Federal de Minas Gerais, comprovam que o aproveitamento dos estudantes cotistas é sempre muito próximo ao dos demais estudantes, com desempenho levemente superior em alguns cursos e com desempenho levemente inferior em outros.

Por último, o que foi destacado para a faixa dos 700 pontos, pode ser aplicado para as demais faixas de desempenho. A diferença, numa escala de 10 pontos, é, quase sem exceção, uma diferença de poucos décimos a favor da ampla concorrência.

Portanto, sem dúvidas, é mito imaginar que a inclusão, nos moldes que está ocorrendo no Brasil hoje, seja de alguma forma responsável pela redução de standards ou pelo afrouxamento dos padrões de qualidade. Este discurso não se sustenta nos dados, e, sim, no preconceito petrificado pelo elitismo histórico de nossa educação básica e superior.

Sob pena de deixar a impressão de que a avaliação se resume ao Enade e ao Enem, ou ao desempenho de estudantes, cabe ainda tecer algumas considerações sobre o nosso sistema de avaliação como um todo, o Sinaes, especialmente no tocante à sua participação na regulação do sistema de educação superior. 
É sempre bom relembrar que o Sinaes foi concebido, antes de qualquer coisa, para a avaliação in loco de cursos e instituições, com o Enade figurando como mero coadjuvante, podendo inclusive ser realizado por amostragem. Embora os objetivos expressos das avaliações no âmbito do Sinaes sejam melhorar a qualidade da educação superior; aumentar a eficácia institucional da educação superior; aumentar a efetividade acadêmica e social da educação superior; e orientar a expansão da oferta de educação superior, é evidente que todas estas qualidades devem ser a base para a regulação. Dez anos após o Programa de Avaliação Institucional das Universidades Brasileiras (Paiub), já com todo aparato jurídico instalado, especialmente da LDB e do PNE de 2001, era impossível imaginar uma avaliação da educação superior nos moldes do Paiub, ou seja, sem esta vinculação estreita com a regulação.

Mesmo assim, é importante deixar claro que os formuladores do Sinaes sempre demonstraram grande respeito pelas discussões em andamento no Brasil e no exterior. E a literatura da avaliação em geral estabelece como funções da avaliação: a função formativa, para aperfeiçoar o objeto da avaliação, seja ele qual for; a função somativa, para regular, selecionar, credenciar, reconhecer, etc.; a função administrativa, para utilização de dados e informações para a tomada de decisões; e a função psicológica, para motivar os participantes a tomarem consciência dos valores afirmados.

$\mathrm{Na}$ formulação do Sinaes, teve-se o cuidado de respeitar o conhecimento expresso na literatura especializada sobre o assunto. Sempre se teve a clareza de estar diante de um Estado avaliador, que já havia, em suas leis maiores, estabelecido funções nitidamente somativas ou regulatórias. Sabia-se que o máximo que era possível fazer, sem promover outra discussão que levasse dez anos, como foi o caso da LDB, que definiu nitidamente as funções regulatórias, era promover as demais funções, buscando instituir a autoavaliação como ponto de partida do processo avaliativo, estabelecer em lei a criação de Comissões Próprias de Autoavaliação, definir a Missão Institucional, o PDI e o PPI como orientadores maiores da avaliação, buscando assegurar, assim, o respeito à identidade institucional. Por último, teve-se o cuidado de assegurar que o ato regulatório, mesmo em casos de graves deficiências encontradas pelas comissões, resultasse não no fechamento imediato de cursos e instituições, mas num protocolo de compromisso que permitisse que a instituição tomasse, em determinado prazo, as medidas cabíveis para a correção das fragilidades, podendo, assim, aprender com os equívocos identificados e evitá-los no futuro.

No mesmo patamar de importância estava a preocupação em definir dimensões para os objetos avaliativos "instituição" e "curso", bem como em assegurar 
que a avaliação de instituições e cursos fosse resultado de avaliação in loco a ser realizada por comissões de especialistas.

A seguir, destaca-se o artigo $3^{\circ}$ da Lei do Sinaes:

Art. $3^{\circ}$ A avaliação das instituições de educação superior terá por objetivo identificar o seu perfil e o significado de sua atuação, por meio de suas atividades, cursos, programas, projetos e setores, considerando as diferentes dimensões institucionais, dentre elas obrigatoriamente as seguintes [...] (BRASIL, 2004, p. 1, grifo nosso).

Destaque-se, também, o $\S 2^{\circ}$ do artigo $3^{\circ}$ : "Para a avaliação das instituições, serão utilizados procedimentos e instrumentos diversificados, dentre os quais a auto-avaliação e a avaliação externa in loco". E, ainda, o $\S 3^{\text {o: }}$ "A avaliação das instituições de educação superior resultará na aplicação de conceitos, ordenados em uma escala com 5 (cinco) níveis, a cada uma das dimensões e ao conjunto das dimensões avaliadas" (BRASIL, 2004, p. 2, grifos nossos).

É importante perceber que as dez dimensões previstas em lei foram definidas como obrigatórias e não como opcionais, ou seja, para a avaliação institucional ocorrer, há que se considerar as dez dimensões previstas em lei. Não considerar as dez dimensões como obrigatórias é invencionice que fere a lei! E mais: cada uma dessas dimensões deve ser avaliada individualmente, devendo lhe ser atribuída nota de 1 a 5 , juntamente com as demais dimensões. Da mesma forma, a avaliação institucional prevê dois momentos: (1) o da autoavaliação, coordenada pela Comissão Própria da Avaliação; e (2) o da avaliação externa, a ser realizada in loco por comissão designada pelo Inep para tal.

Convém igualmente relembrar que a Lei do Sinaes, no seu artigo $2^{\circ}$, Parágrafo único, estabelece que:

Os resultados da avaliação ... constituirão referencial básico dos processos de regulação e supervisão da educação superior, neles compreendidos o credenciamento e a renovação de credenciamento de instituições de educação superior, a autorização, o reconhecimento e a renovação de reconhecimento de cursos de graduação (BRASIL, 2004, p. 1, grifo nosso).

Por que expor estas questões tão óbvias para os que militam há mais tempo na avaliação? Porque, depois de mais de uma década de Sinaes, sem que ele se consolidasse adequadamente, há que se fazer uma limpeza geral no terreno avaliativo. Não é mais possível recuperar os ideais e as ideias centrais do Sinaes com tantos penduricalhos que ridicularizam a doutrina fundamental do sistema.

A que estou me referindo? Primeiro, ao Enade. Ao Enade, não como exame, mas como falso protagonista do sistema. Segundo, aos índices, ao Conceito Prévio de Curso (CPC) e, muito enfaticamente, ao Índice Geral de Cursos (IGC), ambos majoritariamente derivados de um falso protagonista, o Enade. 
Ora, se a lei prevê a avaliação obrigatória de dez dimensões claramente definidas e listadas, como explicar que uma instituição possa ter a sua avaliação finalizada, gerando ato regulatório, com base em um índice, derivado de outro índice, derivado de outros instrumentos que nada têm a ver com as dimensões previstas em lei para cursos e instituições? Querer sustentar, como se faz hoje no MEC, a regulação em um índice derivado principalmente do Enade é, primeiro, uma insensatez, uma aberração técnica; segundo, é uma afronta à Lei do Sinaes, que estabelece dimensões muito claras do que deve ser avaliado, não por perguntas de um questionário socioeconômico, não por respostas de alunos em uma prova de conteúdo, não por posicionamentos de desempenhos diversos numa curva normalizada, mas por inferências e juízos produzidos por pares acadêmicos a partir da análise criteriosa de dados e informações pertinentes às dimensões previstas em lei. Os índices afrontam, hoje, no entanto, não só a Lei do Sinaes, afrontam também o bom senso, pois o credenciamento de instituições e cursos para participarem das principais políticas públicas na esfera educacional (Prouni, Sisu, Fies) alimenta a preguiça com relação ao que é o mais precioso na avaliação: a afirmação de valores. Refiro-me aos valores subjacentes a cada um dos indicadores, das dezenas de indicadores, que compõem os instrumentos de avaliação.

Presenciamos, por isso mesmo, a cada dia que passa, situações inusitadas de (1) cursos que nunca são avaliados (o que significa que dirigentes passam a ter menosprezo pela avaliação in loco e a tudo o que ela significa); (2) cursos de alta qualidade que são impedidos de participarem do Prouni e do Sisu. No caso do Sisu, com o agravante da perda a cada ano de grande quantidade de vagas públicas e gratuitas, porque os alunos ou boicotaram o Enade ou compareceram ao exame apenas para assinar a prova! Exemplifico com o que ocorreu, recentemente, com o curso de Jornalismo de uma conceituada universidade federal do sul do Brasil. Este curso foi impedido pelo MEC de participar do Sisu e mesmo de abrir processo seletivo próprio por ter ficado com CPC 2. Ocorre que, na avaliação in loco, a comissão atribuiu nota 5 ao curso. Ou, ainda, a situação vivida recentemente em IES premiada por um Conselho Estadual de Educação de um estado do sul do Brasil por ter obtido IGC 5. A comissão de avaliação in loco, no entanto, após cuidadosa análise, decidiu atribuir nota 2 a esta instituição, por julgá-la totalmente inadequada para funcionamento em cinco das dez dimensões da avaliação institucional e atendendo apenas ao mínimo exigido nas demais. E assim vai! $\mathrm{O}$ custo acadêmico destes equívocos é alto, pois eles ameaçam os padrões acadêmicos, iludem a população e alimentam a preguiça com relação ao que verdadeiramente importa na avaliação: os valores que a comunidade acadêmica acredita serem fundamentais 
para promover a qualidade. Destaque-se que são poucas as vozes que têm feito esta crítica com a necessária veemência dentro dos quadros do MEC e do Inep.

Estamos, hoje, portanto, além dos desafios da expansão e da inclusão, diante de desafios muito específicos com relação ao Sinaes - desafios que precisam ser enfrentados urgentemente, sob pena de desacreditarmos totalmente a avaliação. Entre esses desafios, cabe destacar os seguintes: (1) deslocar efetivamente o centro da avaliação para a avaliação institucional (esta é a origem do Sinaes e, até prova em contrário, seria fundamental dar à avaliação institucional in loco o protagonismo que lhe é de direito); (2) ampliar ao máximo a integração dos instrumentos de avaliação e de informação desenvolvidos por diferentes órgãos do MEC, de outros ministérios e dos sistemas estaduais. Isso permitirá o melhor aproveitamento dos dados gerados para as políticas de inclusão e expansão, bem como a construção de instrumentos de avaliação mais leves. Isso tornará possível uma dedicação maior aos aspectos qualitativos e interpretativos; (3) institucionalizar programas permanentes de sensibilização da comunidade acadêmica e de capacitação de avaliadores (observação: estudo da Andifes indica que mais da metade dos docentes das instituições federais tem menos de dez anos de casa, ou seja, foram nomeados nos últimos anos e, portanto, não acompanharam o processo de implantação do Sinaes e de outras importantes políticas educacionais. A renovação do corpo docente em ambientes sem estabilidade, como nas IES privadas, faz com que o quadro docente mude constantemente. Com o quadro técnico não é diferente, e os estudantes, por natureza, ficam poucos anos na instituição, sendo que a cada ano novos estudantes ingressam e precisam ser motivados a participar. Por tudo isso, a sensibilização permanente é fundamental); (4) consolidar a cultura da autoavaliação nas IES (o MEC, as Comissões de Avaliação Externa e os fóruns de pró-reitores precisam valorizar mais a Comissão Própria de Avaliação (CPA), pois isto lhes dará mais robustez para enfrentar as resistências dentro do campus. As CPAs devem ser timoneiros dos processos de análise e interpretação dos dados dentro das instituições); (5) acabar com a obsessão pelos índices, o que significa acabar com o protagonismo do Enade. O Enade, com o CPC, deve retornar à sua posição de coadjuvante do sistema, podendo até ser um indicador a mais da avaliação de cursos em tempos de expansão, como previa uma das primeiras portarias do Inep em 2004, mas nunca o seu centro. O IGC, como já destacado, afronta as dez dimensões do Sinaes e deveria ser imediatamente abolido; (6) impedir que a regulação do sistema seja feita com base nos índices, reforçando a legalidade da avaliação no âmbito do Sinaes, mediante a avaliação in loco; (7) nunca privilegiar o uso dos índices sobre os resultados da avaliação in loco em políticas e programas de democratização e inclusão do MEC; (8) implantar e revisar periodicamente as salvaguardas que protegem 
os avaliadores dos agrados excessivos, das tentativas de suborno e às vezes de ameaças explícitas nas avaliações in loco; (9) estruturar o Inep e a Secretaria de Regulação da Educação Superior (Seres), para que possam dar conta das demandas impostas pela expansão da educação superior prevista no PNE 2014-2024; (10) não permitir que a avaliação, a regulação e a supervisão se confundam, mantendo o princípio, consolidado no Decreto $\mathrm{n}^{\mathrm{0}} 5.773$, de 9 de maio de 2006 , de que quem avalia não regula e quem regula não avalia; (11) ser proativo na divulgação de dados e informações disponíveis no MEC relativos aos processos avaliativos e aos sistemas de coletas de informações sobre a educação básica e superior. Quem tem o privilégio de ter amplo acesso aos dados tem a obrigação de torná-los, com a maior brevidade possível, acessíveis à população, em especial à comunidade acadêmica. Acessíveis não só como microdados, que poucos especialistas conseguem ler e transformar em informação, mas como dados traduzidos para uma linguagem que todas as pessoas minimamente educadas entendam. Isso trará mais pessoas bem informadas ao centro das discussões e será bom para o país.

Os desafios gerais para os próximos anos, a julgar pelo PNE aprovado em 2014 e pelas tendências internacionais, precisam ser estes: (1) continuar expandindo (instituições, matrículas, concluintes em todas as regiões do país e em todas as áreas do conhecimento); (2) continuar incluindo (para dar continuidade ao esforço de inclusão, especialmente dos estudantes oriundos de grupos sociais historicamente excluídos e com desabilidades específicas); (3) consolidar uma cultura de qualidade (consolidar o Sinaes, aumentar as taxas de diplomação, reduzir a evasão, combater fábricas de diplomas, reforçar o sistema regulatório, promover intercâmbio de boas práticas, especialmente no âmbito do Mercosul, reforçando o Arcusul). A cultura da qualidade remete-nos necessariamente à premente necessidade de formar professores para a educação básica, para acabar com o improviso que ainda impera em todas as regiões do país e em todas as disciplinas ofertadas, engajando-se decisivamente no processo de valorização da carreira do professor. Precisamos hoje não só assegurar o piso salarial nacional, mas resolver questões sistêmicas que estimulam o improviso, adiam concursos, impedem a educação continuada e transformam escolas em ambientes quase hostis à aprendizagem; (4) fazer uso de novas tecnologias para incluir pessoas de áreas remotas do país, criar oportunidades para pessoas que perderam a idade correta do fluxo educacional (por isso a importância de considerar também a taxa de escolarização bruta, hoje em 30\% e prevista no PNE para atingir 50\% até 2024), promover a educação continuada, reorganizar os currículos, permitindo trajetórias acadêmicas mais diversificadas e flexíveis; (5) internacionalizar (para participar da geração de conhecimento e da construção da cultura da qualidade em contextos supranacionais). Neste aspec- 
to, torna-se importante consolidar as duas universidades internacionais criadas (Unila e Unilab), efetivar a BRICS Network University, a Liga de Universidades dos BRICS, construir a Universidade Aberta do Mercosul e promover iniciativas internacionais no âmbito do reconhecimento de estudos, títulos e diplomas; e, por último, (7) superar os mitos, já discutidos, que atravancam as políticas de inclusão e expansão e impedem a superação do dogma acadêmico elitista e medieval anteriormente referidos.

O sonho da busca de uma educação superior inclusiva e com qualidade há de continuar enquanto tivermos como imagem de futuro uma nação soberana, democrática, inclusiva, emancipatória e capaz de contribuir com a melhoria da qualidade de vida para todos. Este é o sonho que não morre, embora seja por vezes adiado, mas mesmo o sonho adiado, como já lembrava o poeta negro Langston Hughes, um dos militantes da inclusão dos negros na sociedade americana, nutre em nós alguma esperança.

\section{Notas}

1 Disponível em: <http://flacso.org.br/?publication-type=cadernos\&gea=GEA>.

2 Javier Vidal, "Sobre los sistemas de indicadores”, Valência, Espanha, Infoaces, março de 2013.

\section{Referências}

BRASIL. Constituição da República Federativa do Brasil de 1988, com as alterações das Emen-

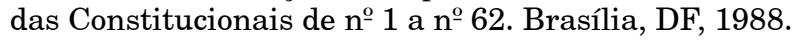

. Lei no 9.131, de 24 de novembro de 1995. Brasília, DF, 1995.

. Lei no 9.394, de 20 de dezembro de 1996 (LDB - estabelece as diretrizes e bases da educação nacional). Brasília, DF, 1996.

$\overline{\mathrm{DF}, 2001 .}$

Lei no 10.172, de 10 de janeiro de 2001 (institui o Plano Nacional de Educação). Brasília,

Lei no 10.861, de 14 de abril de 2004. Brasília, DF, 2004.

. Lei $\mathrm{n}^{\mathrm{0}}$ 11.096, de 13 de janeiro de 2005 (lei que institui o Programa Universidade para Todos - Prouni). Brasília, DF, 2005.

. Decreto no 6.094, de 24 de abril de 2007 (Plano de Metas Compromisso Todos pela Educação). Brasília, DF, 2007a.

Decreto $\mathrm{n}^{\mathrm{o}}$ 6.095, de 24 de abril de 2007 (cria os Institutos Federais de Educação Tecnológica). Brasília, DF, $2007 \mathrm{~b}$.

Decreto $\mathrm{n}^{\circ}$ 6.096, de 24 de abril de 2007 (decreto que institui o Programa de Apoio a Planos de Reestruturação das Universidades Federais - Reuni). Brasília, DF, 2007c. 
. Lei $\mathrm{n}^{\mathrm{o}} 11.502$, de 11 de julho de 2007 (modifica as competências e a estrutura organizacional da Capes). Brasília, DF, 2007d.

Lei $\mathrm{n}^{\mathrm{o}}$ 12.202, de 14 de janeiro de 2010 (que altera do Fundo de Financiamento ao Estudante do Ensino Superior - Fies, definido na Lei 10.260, de 12 de julho de 2001). Brasília, DF, 2010 .

Lei $\mathrm{n}^{\mathrm{o}}$ 12.711, de 29 de agosto de 2012 (Lei de Cotas: dispõe sobre o ingresso nas universidades federais e nas instituições federais de ensino técnico de nível médio). Brasília, DF, 2012a. DF, 2012b.

Decreto no 7.824, de 11 de outubro de 2012. Regulamenta a Lei no 12.711/2012. Brasília,

Lei no 13.005, de 25 de junho de 2014 (Lei do Plano Nacional de Educação 2014-2024). Brasília, DF, 2014.

GARCIA, Francisco Augusto da Costa; JESUS, Girlene Ribeiro de. Uma avaliação do sistema de cotas raciais da Universidade de Brasília. Estudos em Avaliação Educacional, São Paulo, v. 26, n. 61, p. 146-165, jan./abr. 2015.

GOLGHER, André Braz et al. Avaliação de impacto do bônus sociorracial da UFMG no desempenho acadêmico dos estudantes. Mediações, Londrina, v. 19, n. 1, p. 214-248, jan./jun. 2014.

INSTITUTO NACIONAL DE ESTUDOS E PESQUISAS EDUCACIONAIS ANÍSIO TEIXEIRA; MINISTÉRIO DA EDUCAÇÃO. Sinopses Estatísticas da Educação Superior. Brasília: Inep, 2015.

LYONS, F. S. L. The idea of a university: Newman to Robbins. In: PHILLIPSON, Nicholas (Ed.). Universities, Soczety, and the Future. Edimburgo: Edinburgh University Press, 1983.

MENDES JUNIOR, Alvaro Alberto Ferreira. Uma análise da progressão dos alunos cotistas sob a primeira ação afirmativa brasileira no ensino superior: o caso da Universidade do Estado do Rio de Janeiro. Ensaio: Avaliação e Políticas Públicas em Educação, Rio de Janeiro, v. 22, n. 82, p. 31-56, jan./mar. 2014.

NUNES, Edson; CARVALHO, Márcia. O grande equívoco do ensino superior brasileiro: um ensino profissional que não se aplica às profissões que o defendem. Rio de Janeiro: Observatório Universitário, 2006. (Documento de Trabalho nº. 58, publicado em 11 de setembro de 2006).

RISTOFF, Dilvo I. Construindo outra educação. Florianópolis: Insular, 2011.

Universidade em foco. Reflexões sobre a educação superior. Florianópolis: Insular, 1999.

PEIXOTO, Adriano de Lemos Alves et al. Cotas e desempenho acadêmico na UFBA: um estudo a partir dos coeficientes de rendimento. Avaliação, Campinas, v. 21, n. 2, p. 569-591, jul. 2016.

ROBERTS, Edgar V.; JACOBS, Henry E. Literature: an introduction to reading and writing. Englewood Cliffs, New Jersey: Prentice Hall, 1989.

TROW, Martin. Reflections on the transition from elite do mass to universal access: forms and phases of higher education in modern societies since WWII. 2005. Disponível em: <http://repositories.cdlib.org/igs/WP2005-4>.

UNESCO. World Conference on Higher Education: the new dynamics of higher education and research for societal change and development. Paris: UNESCO, 2009.

. Declaração da Conferência Regional de Educação Superior na América Latina e no Caribe. Cartagena: Iesalc, 2008. 